\title{
Carbapenem Resistance Enterobacteriaceae Among Wound Isolates, Kosti City, Sudan
}

\author{
Babiker Saad Almugadam ${ }^{1 *}$, Abdulbagi Saeed Elbala ${ }^{2}$, Abobaker Safe ELdeen Elkheir $^{2}$, Mohammad Abdul Mazid $^{3}$ and Sally Adam Osman ${ }^{4}$ \\ ${ }^{1}$ Department of Microbiology, Faculty of Medical Laboratory Sciences, University of El Imam El Mahdi, Kosti city, Sudan \\ ${ }^{2}$ Lab specialist, Faculty of Medical Laboratory Sciences, University of El Imam El Mahdi, Kosti city, Sudan \\ ${ }^{3}$ Department of Hepatobiliary \& Pancreatic Surgery, The First Affiliated Hospital of Dalian Medical University, China \\ ${ }^{4}$ Lab specialist, Kosti Teaching Hospital, Kosti city, Sudan
}

"Corresponding author: Babiker Saad Almugadam, Department of Microbiology, Faculty of Medical Laboratory Sciences, University of El Imam El Mahdi, Kosti city, Sudan, Tel: 00249917717034; Email: Babiker888@yahoo.com

Received date: December 19, 2017; Accepted date: January 4, 2018; Published date: January 8, 2018

Copyright: @2018 Almugadam BS, et al. This is an open-access article distributed under the terms of the Creative Commons Attribution License, which permits unrestricted use, distribution, and reproduction in any medium, provided the original author and source are credited.

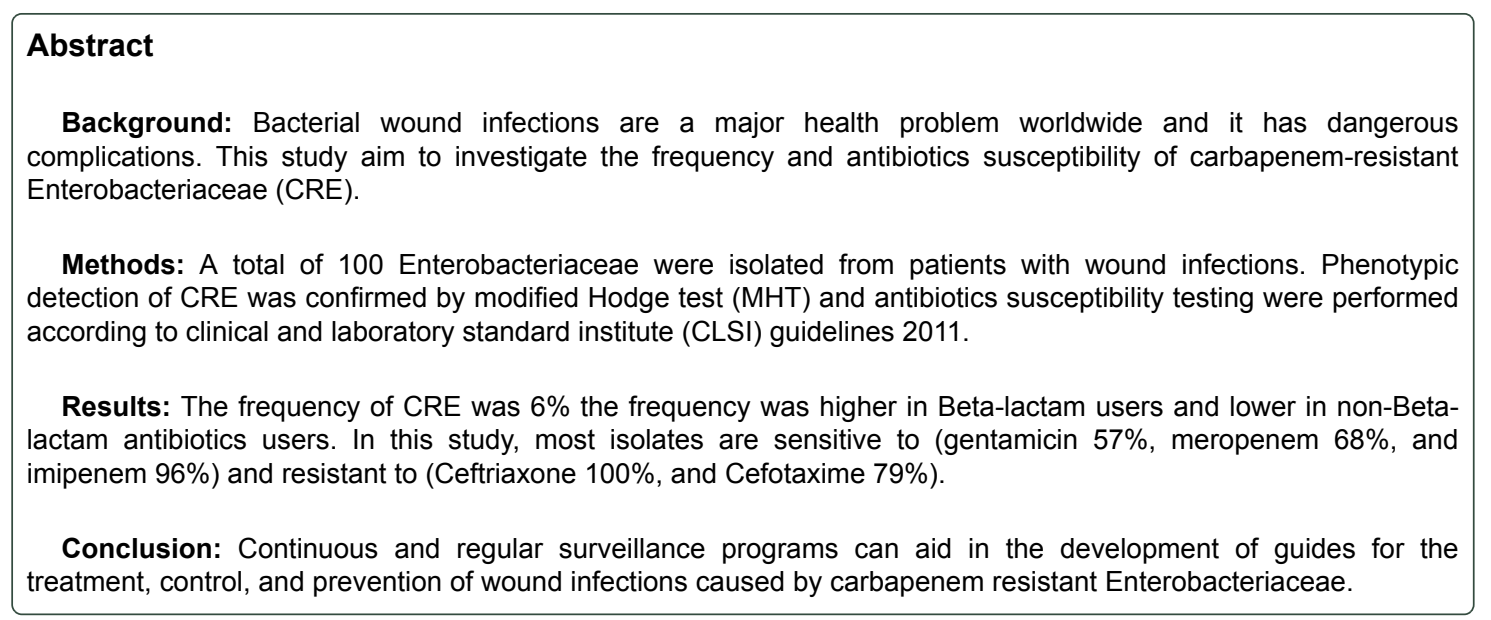

Keywords: Antimicrobial resistance; CRE; MHT; Sudan; Wound infection

\section{Introduction}

A wound is a damaged area of the body, usually involving a break to the skin. Wounds can be surgical or due to traum [1]. Wound infections may cause by viruses, fungi, parasite, and bacteria. Enterobacteriaceae family is a one of the major cause of bacterial wound infection [2]. Bacterial wound infections are a major health problem worldwide and it has dangerous complications [2]. Enterobacteriaceae are a large, heterogeneous group of Gram negative rods whose are natural habitat in the intestinal tract of humans and animals [3]. There are many genera of Enterobacteriaceae causes wound infections but this study restricted on E. coli, K. pneumoniae, $P$. mirabilis, E. aerogenes, and $C$. freundii [4]. Enterobacteriaceae developed resistance to many antibiotics, although this study was interesting in the resistance of Enterobacteriaceae to carbamenem antibiotics. Carbapenem resistant occur by two mechanisms, either production of carbapenemases that breakdown carbapenem or production of extended spectrum Beta lactamases (ESBLs) together with porin loss [5]. This study aim to investigate the frequency and antibiotics susceptibility of CRE that isolated from patients with wound infections in order to provide guidance for the treatment of wound infections caused by those pathogen in Kosti city, White Nile state, Sudan.

\section{Materials and Methods}

This study is a cross sectional, hospital based study, carried out in Kosti Teaching Hospital-Kosti city during the period from October 2016 to August 2017. A total of 100 Enterobacteriaceae isolates $(P$. mirabilis $33, K$. pneumoniae $25, E$. coli $23, E$. aerogenes 11 , and $C$. freundii 8 ) were collected from patients with wound infections. All isolates were presumptively identified based on their culture characteristics, Gram stain, and conventional biochemical tests [6]. All isolated Enterobacteriaceae were further subjected to antibiotics susceptibility testing using modified Kirby Bauer disk diffusion technique according to Clinical and Laboratory Standards Institute (CLSI) guidelines 2011, and phenotypic detection for carbapenem resistance using modified Hodge test [7].

Antibiotics Susceptibility testing were performed by modified Kirby Bauer disk diffusion technique according to CLSI guidelines 2011 using Bioanalyse antibiotics which includes amoxyclav $30 \mu \mathrm{g}$, ceftriaxone $30 \mu \mathrm{g}$, cefotaxime $30 \mu \mathrm{g}$, and gentamycin $10 \mu \mathrm{g}$. Inoculum suspension of test organism equivalent to $0.5 \mathrm{McF}$ arland standards was prepared, and by using sterile cotton tipped swab the inoculum suspension was inoculated in Mueller Hinton agar (Himedia media), then with sterile forceps the antimicrobial discs were placed on inoculated media, incubated aerobically at $35^{\circ} \mathrm{C}$ for $18 \mathrm{~h}$. The diameter of inhibition zones were measured in $\mathrm{mm}$ with ruller, and interpreated according to Clinical and Laboratory Standards Institute guidelines 2011 [7]. E. coli ATCC 25922 strain was used as control strain. 
Citation: Almugadam BS, Elbala AS, Elkheir ASE, Mazid MA, Osman SA (2018) Carbapenem Resistance Enterobacteriaceae Among Wound

Page 2 of 3

The screening for carbapenem resistance were performed a long with susceptibility testing by using meropenem $10 \mu \mathrm{g}$, and imipenem $10 \mu \mathrm{g}$ discs. Each isolate showed resistant to meropenem $10 \mu \mathrm{g}$ or/and imipenem $10 \mu \mathrm{g}$ was confirmed for Carbapenem resistance by using modified Hodge test $[7,8]$.

Modified Hodge test was performed for each isolate showed resistant to meropenem or imipenem. Inoculum suspension of $E$. coli ATCC 25922 strain equivalent to 0.5 McFarland standard were prepared, diluted in 1:10 with normal saline, then using sterile cotton tipped swab the diluted suspension were inoculated in Mueller Hinton $(\mathrm{MH})$ agar. Using sterile forceps, meropenem $10 \mu \mathrm{g}$ disk was placed on the center of inoculated plate, then with sterile wire loop the colonies of test organism were streaked from edge of disk to edge of $\mathrm{MH}$ agar plate, incubated aerobically at $35^{\circ} \mathrm{C}$ for $18 \mathrm{~h}$. Positive strain shows a 'cloverleaf shaped' zone of inhibition due to carbapenemase production, while the negative strain shows an undistorted zone of inhibition $[7,9]$.

All the Data were analyzed using statistical package for social sciences (SPSS version 16) software, and $\mathrm{P}$ value $\leq 0.05$ were considered significant in comparative data.

\section{Results}

A total of 100 Enterobacteriaceae isolates ( $P$. mirabilis 33, $K$. pneumoniae 25, E. coli 23, E. aerogenes 11, and $C$. freundii 8) were collected from wound infected patients. The frequency of CRE among isolates is $6 \%$; the frequency was higher in females $8.3 \%(2 / 24)$ than males $5.2 \%(4 / 76)$ as shown in table 1 . The frequency of carbapenem resistant among isolates was $6 \%(2 / 33)$ in $P$. mirabilis, $12 \%(3 / 25)$ in $K$. pneumoniae, and $9 \%(1 / 11)$ in E. aerogenes as shown in table 2.

In this study, most isolates were sensitive to (IPM 96\%, MEM 68\%, and CN 57\%) and resistant to (CTR 100\%, CTX 79\%, and AMC 69\%) as seen in table 3 .

\begin{tabular}{|l|l|l|l|}
\hline \multicolumn{2}{|l|}{ Frequency } & \\
\hline Sex & Carbapenem resistant & Carbapenem sensitive & Total \\
\hline Male & $4(5.3 \%)$ & $72(94.7 \%)$ & 76 \\
\hline Female & $2(8.3 \%)$ & $22(91.7 \%)$ & 24 \\
\hline Total & $6(6 \%)$ & $94(94 \%)$ & 100 \\
\hline
\end{tabular}

Table 1: The frequency of CRE isolates among sex.

The frequency of carbapenems resistant was higher in females $8.35 \%(2 / 24)$ than male $5.3 \%(4 / 76)$.

\begin{tabular}{|l|l|l|l|}
\hline \multirow{2}{*}{ Type of bacteria } & \multicolumn{2}{|l|}{ Frequency } & Total \\
\cline { 2 - 4 } & $\begin{array}{l}\text { Carbapenem } \\
\text { Sensitive }\end{array}$ & $\begin{array}{l}\text { Carbapenem } \\
\text { Resistant }\end{array}$ & \multirow{2}{*}{33} \\
\hline P. mirabilis & $31(94 \%)$ & $2(6 \%)$ & 25 \\
\hline K. pneumoniae & $22(88 \%)$ & $3(12 \%)$ & 11 \\
\hline E. aerogenes & $10(91 \%)$ & $1(9 \%)$ & 8 \\
\hline C. freundii & $8(100 \%)$ & $0(0 \%)$ & 23 \\
\hline E. coli & $23(100 \%)$ & $0(0 \%)$ & \\
\hline
\end{tabular}

\begin{tabular}{|l|l|l|l|}
\hline Total & 94 & 6 & 100 \\
\hline
\end{tabular}

Table 2: The frequency of carbapenem resistance among Enterobacteriaceae isolates.

The higher frequency of carbapenem resistant was shown in $K$. pneumoniae $12 \%(3 / 25)$ followed by $E$. aerogenes $9 \%(1 / 11)$ and $P$. mirabilis $6 \%(2 / 33)$ while the frequency was zero in $E$. coli and $C$. freundii.

\begin{tabular}{|c|c|c|c|c|}
\hline \multirow{2}{*}{\multicolumn{2}{|c|}{ Antibiotics }} & \multicolumn{2}{|c|}{ Frequency } & \multirow{4}{*}{$\begin{array}{l}P \text { value } \\
0.639\end{array}$} \\
\hline & & \multirow{3}{*}{$\begin{array}{l}\text { CRE } \\
0 \\
6\end{array}$} & \multirow{3}{*}{\begin{tabular}{|l} 
Non CRE \\
7 \\
87 \\
\end{tabular}} & \\
\hline \multirow{2}{*}{ CTX } & S 7 (7\%) & & & \\
\hline & R 93 (93\%) & & & \\
\hline \multirow{2}{*}{ CTR } & S $0(0 \%)$ & 0 & 0 & \multirow{2}{*}{0.639} \\
\hline & R 100 (100\%) & 6 & 94 & \\
\hline \multirow{2}{*}{ AMC } & S $23(23 \%)$ & 1 & 22 & \multirow{2}{*}{0.58} \\
\hline & R 77 (77\%) & 5 & 72 & \\
\hline \multirow{2}{*}{ GEN } & S $53(53 \%)$ & 0 & 53 & \multirow{2}{*}{0.009} \\
\hline & R 47 (47\%) & 6 & 41 & \\
\hline \multirow{2}{*}{ MEM } & S $76(76 \%)$ & 2 & 74 & \multirow{2}{*}{0.028} \\
\hline & R 24 (24\%) & 4 & 20 & \\
\hline \multirow{2}{*}{ IMP } & S 96 (96\%) & 5 & 91 & \multirow{2}{*}{0.222} \\
\hline & R $4(4 \%)$ & 1 & 3 & \\
\hline
\end{tabular}

Table 3: The susceptibility of isolated CRE and non CRE to antibiotics.

\section{Discussion}

Regardless of advances techniques and technology in wound management, wound infections are still a major health problem particularly in the developing world, so the frequent detection and evaluation of the susceptibility of pathogens to antibiotics empirically prescribed for eradication of infections [10].

In this study, the frequency of CRE among all isolates was $6 \%$, and it was slightly lower in males $5.4 \%(4 / 76)$ when compared with females 8.3\% (2/24). This result was disagreeing with Henkhoneng $M$ study (India, 2014) which report the frequency of CRE was 70\% [11]. Our result was lower when compared with Henkhoneng $M$ study; these differences in results may arise from the differences in sample sizes or study areas.

In our study, the frequency of carbapenem resistance among $K$. pneumoniae, E. aerogenes, P. mirabilis, E. coli, and C. freundii isolates were $12 \%(3 / 25), 9 \%(1 / 11), 6 \%(2 / 33), 0 \%(0 / 23)$, and $0 \%(0 / 8)$ respectively. This result agree with Irmak B study (turkey, 2016) which report the frequency of carbapenem resistance among $C$. freundii was $0 \%$ and disagree with it, as it reported the frequency of CRE among $E$. aerogenes was $0 \%$ [12]. The higher frequency of carbapenem resistance 
Citation: Almugadam BS, Elbala AS, Elkheir ASE, Mazid MA, Osman SA (2018) Carbapenem Resistance Enterobacteriaceae Among Wound Isolates, Kosti City, Sudan. Clin Microbiol 7: 305. doi:10.4172/2327-5073.1000305

Page 3 of 3

in E. aerogenes in our study when compared with Irmak B may due to differences in study area and sample size.

In this study, all isolates were resistant to Ceftriaxone $100 \%$; and the most isolates were resistant to (Cefotaxime $79 \%$ and Amoxacilinclavulnic acid 69\%) and sensitive to (Imipenem 96\%, Meropenem 68\%, and Gentamycin 57\%). Also all E. aerogenes isolates were sensitive to Amoxyclav and gentamicin. And all $P$. mirabilis isolates were resistant to Ceftriaxone and Cefotaxime, so our data suggests that these drugs are of very limited value in the prophylaxis or empiric treatment of wound infections.

\section{Conclusions}

CRE isolates were more resistant to others antibiotics than non CRE that may suggest the carbapenem resistant is associated with resistant to other antibiotics. Since carbapenem are the drugs of last resort in the treatment of infections caused by multidrug resistant Enterobacteriaceae, the increase of CRE isolates can limit the therapeutic options. Proper wound care and regular update of antibiotics susceptibility through continuous surveillance is essential to maintain good infection control program.

\section{References}

1. NICE interactive flowchart-Skin conditions (2011) The MIST Therapy system for the promotion of wound healing. 1-20.

2. Cooper R, Kingsley A, White R (2003) Wound Infection and Microbiology; Medical Communications (UK) Ltd for Johnson \& Johnson Medical.
3. Brooks GF, Carroll KC, Butel JS, Morse SA (2013) Jawetz Melinck \& Adelberg's Medical Microbiology, Twenty-Sixth Edition, New York Chicago San Francisco Lisbon London Madrid Mexico City Milan New Delhi San Juan Seoul Singapore Sydney Toronto.

4. European Centre for Disease Prevention and Control (2011) Antimicrobial resistance surveillance in Europe 2011. Annual report of the European antimicrobial resistance surveillance network (ears-net). Stockholm: ECDC; 2012. 2012.

5. Little ML, Qin X, Zerr DM, Weissman SJ (2012) Molecular diversity in mechanisms of carbapenem resistance in paediatric Enterobacteriaceae. Int J Antimicrob Agents 39: 52-57.

6. Koneman EW, Allens SO, Janda WM, Schreck-enberger PC, Winn WC (2006) Colour Atlas and Textbook for Diagnostic Microbiology. 4th ed. Philadelphia: JB Lippincott Company. The Enterobactericeae 61-402.

7. Cockerill FR, Wikler MA, Bush K, Dudley MN, Eliopoulos GM, et al. (2011) Performance standards for antimicrobial susceptibility testing: twenty-first informational supplement. CLSI 31.

8. Costerton JW, Stewart PS, Greenberg EP (1999) Bacterial biofilms: a common cause of persistent infections. Science 284: 1318-1322.

9. Sathya P, Shamsadh B, Anbumani N (2015) Phenotypic Detection Methods of Carbapenemase Production in Enterobacteriaceae. Int J Curr Microbiol App Sci 4: 547-552.

10. Loefler IJP (1998) Surgical wound infection in the Third World: the African experi-ence. J Med Microbiol 47: 471-473.

11. Mate H, Devi S, Devi KM, Damrolien S, Devi NL, et al. (2014) Prevalence of Carbapenem Resistance among Gram negative Bacteria in a Tertiary Care Hospital in North-East India. IOSR-JDMS 3: 56-60.

12. Baran I, Aksu N (2016) Phenotypic and genotypic characteristics of carbap- enem resistant Enterobacteriaceae in a tertiary-level reference hospiatl in Turkey. Ann Clin Microbiol Antimicrob 15: 20. 